\title{
Plenary Session 2:
}

Climate Change:

From Mitigation to

Adaptation.

A Common Concern

for the Alps and

Adjacent Metropolises

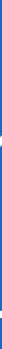




\section{Introduction}

\section{Presentation: Heinz Veit}

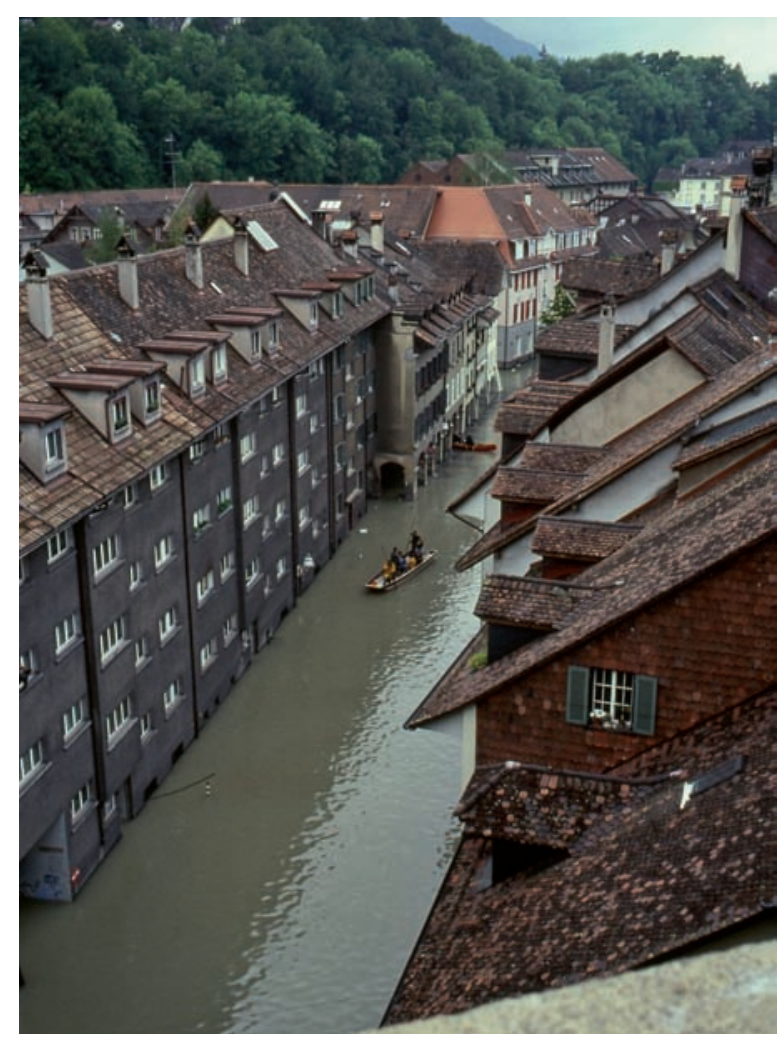

Fig. 1: The 1999 Flood of the Aare-River in the City of Bern, Switzerland.

Climate change is a fact worldwide. Meteorological parameters like mean and extreme temperatures and precipitation have changed during the last decades and will do so in the near future, enhanced by human influence. These changes will affect landscapes and environmental processes as well as societies and individuals. Therefore, mitigation and adaptation to climate change are major issues in planning our future.
The Alps and surrounding metropolises will have mutual concerns, like the availability and sustainable use of water, changes in runoff, natural risks and highland/lowland driven processes. This topic will be the focus of the contribution of Martin Beniston.

Climate change will also influence health and tourism, with possible migrations from hot towns to cooler and cleaner Alps. Combining meteorological and tourism related components, Andreas Matzarakis will discuss these health aspects in the light of his "Climate-Tourism-Information-Scheme" and possible adaptations in urban areas.

The more global perspective of adaptation to climate change with alternative energy systems will be presented by Stefan Schleicher.

Finally, Blanka Bartol will present the "Climate Action Plan" of the Alpine Convention, adopted in 2009 and focusing on the goal of climate neutral Alps by the year 2050 .

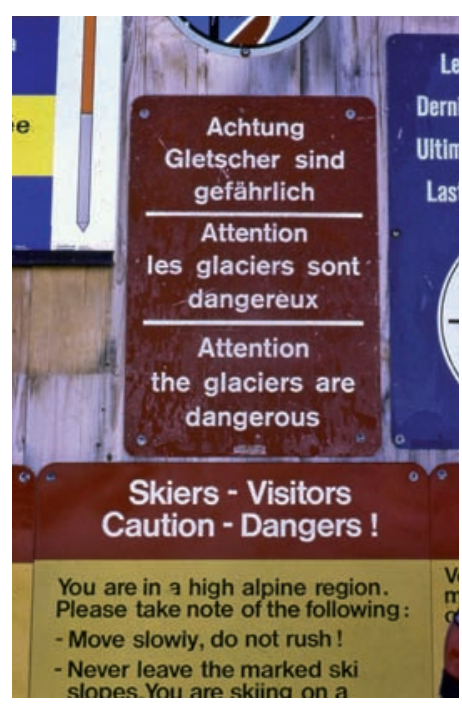

Fig. 2: In a changing climate, tourism will change, and glaciers too. Signs at Saas Fee, Switzerland. 


\title{
Impacts of Climatic Change in the Alps: Consequences for the Availability and Use of Water
}

\author{
Martin Beniston
}

Mountains are recognized as particularly sensitive physical environments where climatic change would considerably influence the runoff regime of the rivers downstream and the related water availability. Increasing evidence of glacier retreat, permafrost reduction and snowfall decrease have been observed in many mountain regions, with subsequent alterations of stream flow regimes. If these trends accelerate in the future, they would in turn threaten the availability of water resources, increase downstream landslide and flood risk, and impact hydropower generation, agriculture, forestry, tourism and aquatic ecosystems. As a consequence, socio-economic structures of populations living downstream would also be impacted, calling for better preparedness and improved water governance.

Water is relevant in every aspect of mountain systems, in the physical, biological and socio-economic systems. It directly influences the energy supply (hydropower), tourism (snow, water usage, glaciers), forestry and agriculture (productivity changes with changes in water supply, need for irrigation) and services from natural and semi-natural ecosystems. On the other hand changes in any of these compartments will affect water availability. Increased competition for water among many socio-economic sectors may arise, requiring regulatory or market mechanisms to attenuate tension and assure efficient and equitable use. Achieving sustainable water use poses particular challenges for policy making because of its nature as a public good and because it often has both upstream/ downstream and trans-boundary characteristics.

The Alps in general, and Switzerland in particular, have in the past been referred to as "the water tower of Europe" (Mountain Agenda 1998), as they are the source region for many rivers that flow through Western and Central Europe, as well as towards the Mediterranean Sea. Any substantial changes in the mountain snow pack would have a significant impact on the flow of many major river basins, not only because of changes in the amount and timing of runoff, but also because of the potential for enhanced flooding, erosion, and associated natural hazards. A major EU project (ACQWA: Assessing Climate Impacts on the Quantity and Quality of Water, Framework Programme 7; www.acqwa. ch), coordinated by the Institute of Environmental Sciences at the University of Geneva, is currently underway to investigate not only the physical response of mountain hydrological systems, but also the environmental and socio-economic responses to changes in water availability. This involves focusing on a range of impacts, such as natural hazards, aquatic ecosystems, hydropower, tourism, agriculture, and the health implications of changing water quality. Among the regions of particular focus, the Rhone and Pô catchments in the Alps, the Aconcagua Valley in Chile, and the rivers of Kyrgyzstan serve as examples of contrasting water resources and approaches to water governance issues.

In the Swiss Alps, regional climate model (RCM) results show fairly consistent trends in both temperature and precipitation by 2100 . For the IPCC (2007) A-2 greenhouse-gas emissions scenario, average 30-year temperatures (2071-2100) are expected to rise by close to $4^{\circ} \mathrm{C}$ in winter and by over $6^{\circ} \mathrm{C}$ in summer compared to the baseline climate (1961-1990). Seasonal change in precipitation between scenario and baseline climate exhibits a substantial rise of wintertime precipitation but significantly curtailed summertime rainfall (e.g., Beniston 2006). 
In a scenario climate, warmer conditions associated with enhanced precipitation in the Alps are likely to lead to more abundant snowfall in the higher reaches of the mountains, but much reduced snow at lower levels where precipitation is more likely to fall in the form of rain. Beniston et al. (2003) have shown that the crossover level where snow becomes more abundant under milder conditions may be located between 1,700 and 2,000 m above sea level. The same study suggests a dominant influence of temperature on snow duration compared to precipitation, with small shifts in mean winter temperature leading to substantial changes in the length of the season.

In terms of Alpine ice cover, the glaciers in Switzerland and its neighbours have lost between 30 and $40 \%$ of their surface area and about half of their volume since 1900. Empirical and energy-balance models indicate that $30-50 \%$ of the existing mountain glacier mass could disappear by 2050 if global warming scenarios in the range of $2-4^{\circ} \mathrm{C}$ were to occur (Haeberli \& Beniston 1998). Projections from regional climate models suggest that in the Alpine region, warming will be accompanied by an average reduction of annual precipitation, thereby implying rapidly waning glaciers until they find perhaps another equilibrium at much higher elevations and with substantially reduced volume and surface area; some may disappear entirely if the equilibrium line altitude is positioned above that of the glacier catchment area.

Alpine water resources are strongly influenced by mountain climates that govern soil moisture, groundwater recharge, evaporation and runoff. For example, the Rhone river discharges are controlled by evaporation, precipitation, storage of water in artificial reservoirs, and melt water from snow and ice. Precipitation throughout the year, and snow and ice melt waters from April to October provide input to the river basin; in addition, hydro-power utilities release water into the catchments and tributaries of the Rhone during the winter half-year in order to generate power during the peak energy demand period of the winter. Water is locked in the winter snow-pack on average from November to May, while evaporation reaches a maximum during the summer months. Dams retain a small part of snow-melt and precipitation during the summer months and store this water to prepare for supplying energy later in the year; this storage removes water from the system that would otherwise contribute directly to runoff.

Because precipitation is fairly evenly distributed throughout the year and storage of water in dams represents a small fraction of the total amounts of water involved, the most important seasonal signal in terms of runoff is determined by the Alpine snow-pack, in particular the timing of snow-melt and the amount of melt-water which is a function of the quantity of snow accumulated during the preceding winter. It is this signal unique to high mountain regions that would be substantially altered by a much warmer climate.

In a scenario climate, runoff by 2100 is seen to change in seasonality and amount compared to the current climate (Fig. 1). There is a first peak of discharge that takes place $2-3$ months earlier in the year, and according to the level of warming, a sec-

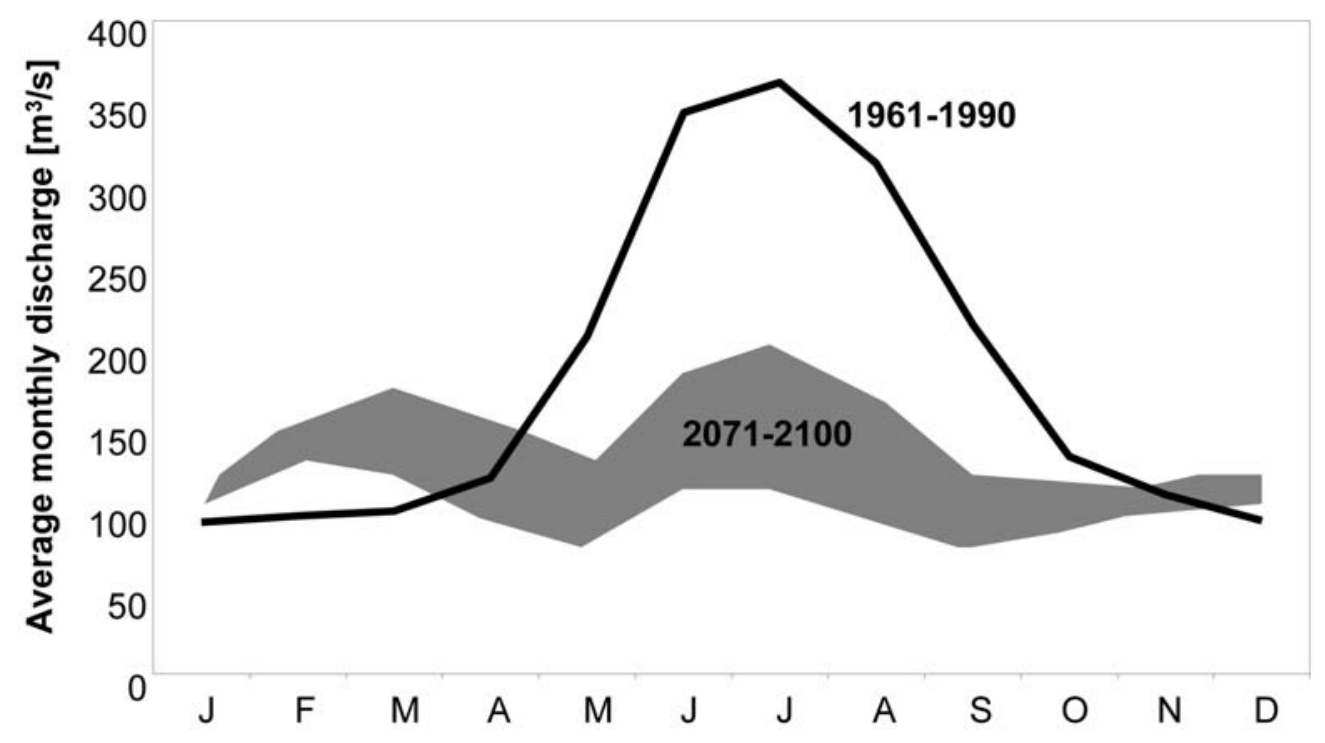

Fig. 1: Changes in Monthly Discharge of the Rhone River Close to its Mouth in the Lake of Geneva, Near Montreux, Switzerland, from Current (1961-1990) to Future (2071-2100, IPCC A2 Emissions Scenario).

The gray shading gives the possible range of discharge, according to the timing and volume of snow melt, estimates of glacier retreat, and shifts in seasonal precipitation. 
ond peak of discharge takes place during the summer. This summer peak would occur if the number and volume of remaining glaciers were to be sufficient to contribute to such levels of discharge. At the lower end of the possible range of future discharge, summertime flows are seen to be lower than during the spring; this would be the case with the quasi-disappearance of glaciers in the source region. Whatever the absolute value of future discharge, maximum flows are reduced compared to the reference period because of the smaller contributions of a dwindling winter snow-pack. In addition to changing snow and ice, the modest peak of summertime discharge seen in this figure is also linked to convective activity that could still occur despite the strong reduction projected for summer rainfall. The gray shading gives an estimated range of uncertainty of the results, according to the amount of snow and the timing of spring melt, the estimated remaining glacier mass, and shifts in seasonal precipitation. These are typically the quantities that the ACQWA project is seeking to refine for improved estimates of river flows.

Because of the large interannual variability of runoff, as a result of the sharply curtailed glacier mass in the mountains and possibly long and dry summers, the volume of summertime glacier melt waters may no longer be sufficient to feed water into river catchments at a time of the year when precipitation amounts are low and the snow-pack has already melted earlier in the year. Consequently, in some years, the Rhone may dry up partially or completely towards the end of the summer and into the early fall. The future characteristics of runoff shown in this figure are more typical of rivers that are currently found in the Mediterranean parts of the Alps, as in the French Provence region and in parts of the Italian-facing slopes of the Alpine arc, for example.

A changing climate leading to modifications in hydrological regimes has the potential to increase competition over water that will be available at different times and in different quantities compared to today. Water is difficult to allocate because of its public good features, which are aggravated by upstream potential to capture the resource and by the fact that flowing water may cross internal and international borders. Adding further to the potential for conflict are socio-economic changes that modify existing distribution schemes. Because of conflicting water use (e.g., between agriculture and hydropower, or between hydropower and tourism) as the resource diminishes through reduced precipitation in some areas and glacier retreat in others, one needs to acknowledge the fact that new water resource management is not just a matter of adjusting to shifts in the physical environment. Such management also needs to be strongly associated with social changes that are generated by shifts in the type and level of water use and new market conditions that are capable of affecting distribution.

\section{References}

Beniston, M. (2006): The August 2005 Intense Rainfall Event in Switzerland: Not Necessarily an Analog for Strong Convective Events in a Greenhouse Climate. Geophysical Research Letters, 33, L5701.

Beniston, M., F. Keller, B. Koffi et al. (2003): Estimates of Snow Accumulation and Volume in the Swiss Alps under Changing Climatic Conditions. Theoretical and Applied Climatology 76: 125-140.

Haeberli, W. \& M. Beniston (1998): Climate Change and its Impacts on Glaciers and Permafrost in the Alps. Ambio 27: 258-265.

IPCC (2007): Climatic Change; the Intergovernmental Panel on Climate Change Fourth Assessment Report. Cambridge University Press, Cambridge (Volume I: Science; Volume II: Impacts; Volume III: Adaptation and Mitigation).

Mountain Agenda (1998): Mountains of the World. Water Towers for the 21st Century, Prepared for the United Nations Commission on Sustainable Development. Institut für Geographie, Universität Bern, und Direktion für Entwicklung und Zusammenarbeit im Eidgenössischen Departement für auswärtige Angelegenheiten (Institute of Geography, University of Bern and Swiss Agency for Development and Cooperation). Haupt, Bern. 


\title{
Assessment of Weather and Climate for Tourism and Health in the Alps
}

\author{
Andreas Matzarakis
}

It is common knowledge that weather and climate affect human beings. Beside weather and climate other factors such as geographical location, topography, landscape, vegetation, and fauna are factors that influence decisions regarding areas to be visited for tourism. It is a fact that weather/climate and tourism/recreation are interconnected in diverse ways, and tourists, tour organizers, travel agencies, tourism planners, and stakeholders for example need to be reliably informed and educated about the role of weather and climate in tourism and health issues (Matzarakis 2006). This knowledge of weather and information about climate and its application can assist tourism planning and tourism industries in reducing negative effects in the economy sector (Scott et al. 2009). General knowledge of climate parameters (based on thresholds) and their appropriateness for tourism and recreation are basic information, i.e. too much high sun load or strong winds. Climate extremes, e.g. heat waves or storms are most relevant because of the possible damages on infrastructure and human life. A useful climate advisory service will help to prepare and protect tourists and groups at risk (e.g. retirees, sick people, and children).

Since the discussion about climate change and its implications in tourism and human health is still ongoing, an additional aim is to quantify expected bio-climatological and relevant tourism climatological factors. This can be performed by using the Climate-Tourism-Information-Scheme, which includes the most relevant and reliable parameters and tourism-climatological factors. The quantification of climate can be performed by the use of existing climate data set modeled for the present or for the future (Matzarakis et al. 2009).
The recent discussion on climate change issues is focused on the development of mitigation and adaptation strategies. But information about climate change is presented in form of changes in the mean air temperature or changes in precipitation amounts for future climatic periods on a global and on regional scales. More relevant is the quantification of extreme events, not only the trend of climatic variables. Concerning tourism there is a lack of different spatial and temporal scales. The effects of climate change will occur based on events and will take place on the local level where humans live and spend their time during the day and the year. Recent adaptation possibilities are focused on climate protection issues.

In order to assess the climatic tourism potential for human health air temperature and precipitation are not sufficient enough. For example, winter sports enthusiasts and tourists desire snow as well as sunshine, beneficial thermal conditions, and recreation in their holidays. Nowadays, the assessment can be performed by facets of climate in tourism (thermal, aesthetical and physical facet) (de Freitas 2003). The thermal facet of climate is based on a complex thermal index, e.g. PET, which is based on the human energy balance. It describes the effect of the climate not only for cold but also for warm conditions. In general, PET (physiologically equivalent temperature) describes the effect of the thermal surroundings of the human body and includes the energy exchange between humans and environment and assesses the effect of the thermal environment. The other two facets, the aesthetical and physical, can be covered by simple and easy extracted parameters and factors, e.g. snow height and daily sunshine duration from data records or networks (Matzarakis 2006). 


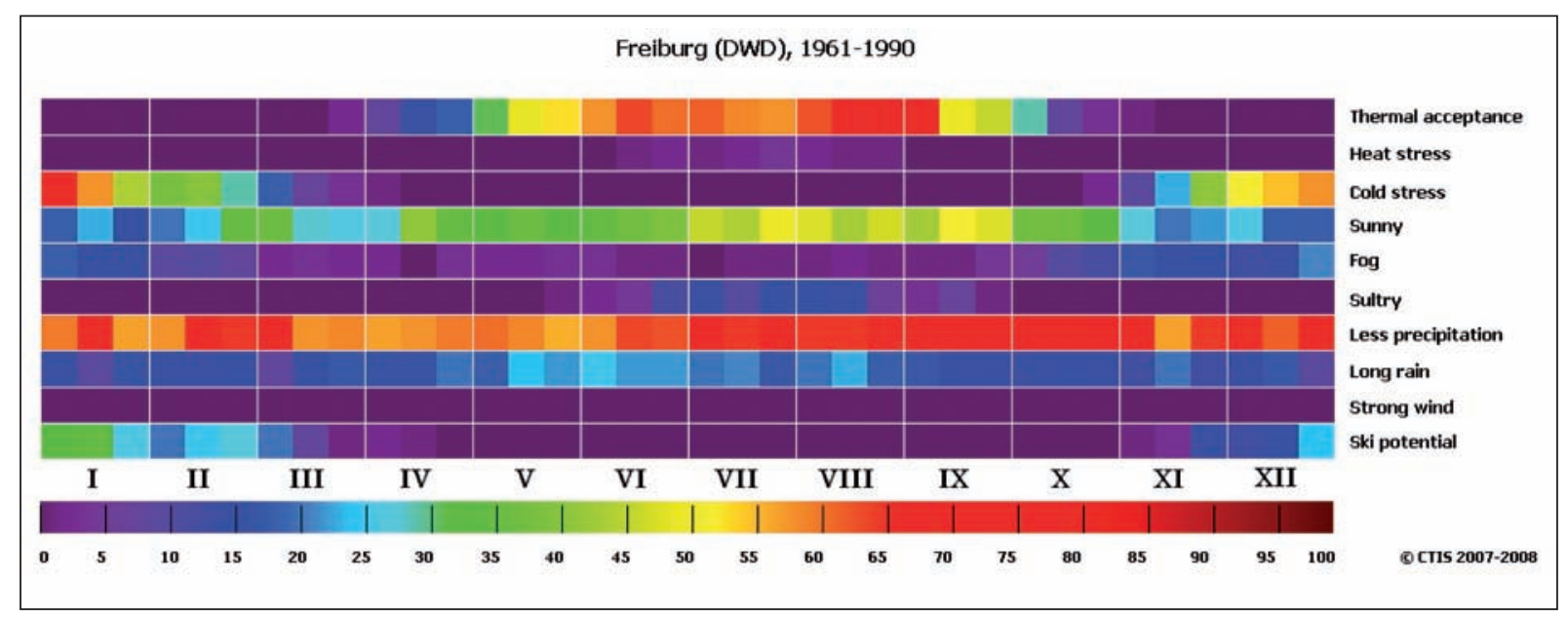

Fig. 1: CTIS for Freiburg for the Period 1961-1990.

Depending on the objectives of the evaluation, these meteorological parameters can be measured or calculated in a grid-net by numerical models.

Here, a new approach based on climate thresholds (Climate-Tourism-Information-Scheme) is presented. The method combines meteorological and tourism related components. Thus, besides the two variables most frequently used in impact assessment studies (air temperature and precipitation), also physiologically equivalent temperature (PET), cold stress (PET $\left.<\mathrm{O}^{\circ} \mathrm{C}\right)$, heat stress (PET $>35^{\circ} \mathrm{C}$ ), thermal comfort $\left(18{ }^{\circ} \mathrm{C}<\mathrm{PET}<29^{\circ} \mathrm{C}\right)$, sunshine/ cloud cover conditions in terms of the number of days with a cloud cover $<5$ octas, vapour pressure $>18 \mathrm{hPa}$, wind velocity $>8 \mathrm{~m} / \mathrm{s}$, relative humidity $>$ $93 \%$, precipitation $<1 \mathrm{~mm}$ as well as precipitation $>5 \mathrm{~mm}$, and snow cover $>10 \mathrm{~cm}$ are considered. In general, the definitions of the several threshold val- ues do not necessarily correspond to the universal meteorological threshold values and are adjusted to applied tourism climatology and human health applications. For example, under meteorological aspects, a stormy day is given by a wind strength of at least $8 \mathrm{Bft}$, which corresponds to a wind velocity greater than $17.2 \mathrm{~m} / \mathrm{s}$, while in tourism climatology a wind velocity of $8 \mathrm{~m} / \mathrm{s}$ ( $5 \mathrm{Bft}$ ) is perceived as unpleasant and uncomfortable. All the above-mentioned factors have been included in an information scheme in order to describe these factors in a high temporal resolution.

The Climate-Tourism-Information-Scheme (CTIS) (Matzarakis 2007) was derived to integrate and simplify climate information for tourism. CTIS contains detailed climate information which can be used by tourists to anticipate thermal comfort as well as aesthetical and physical conditions for

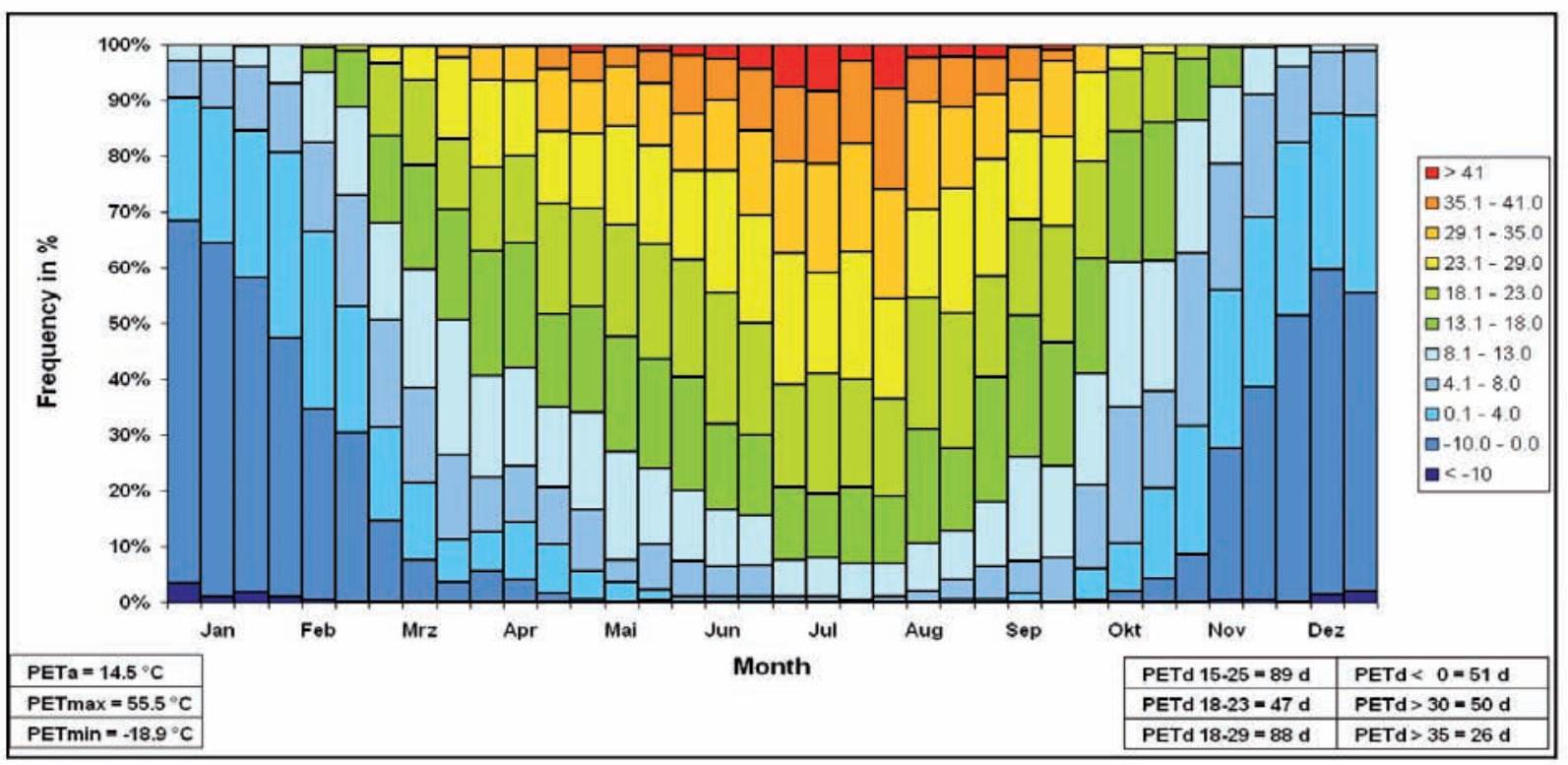

Fig. 2: Bioclimate Diagram (PET) for Freiburg for the Period 1961-1990. 
planning their vacations. CTIS provides all-seasonal frequency classes and frequencies of extreme weather events on a 10-day or monthly time scale (Matzarakis 2007). This method is preferred for analysing climate stations or grid points. Since the results presented here are based on models and thus influenced by the models' uncertainties, a temporal resolution finer than 1 month is not considered to be useful. Each coloured column describes the corresponding frequency of any parameter or factor. A frequency of $100 \%$ indicates that each day in a month is characterized by the respective condition listed on the right hand side. A frequency of $50 \%$ corresponds to an occurrence of the indicated condition during 15 days, $10 \%$ to 3 days of the con- tourism possibilities based on CTIS can be assessed and quantified and periods with occurrences of specific extremes, e.g. heat waves or periods of strong wind, can be detected.

In addition, in order to get any information about adaptation possibilities to climate change conditions, two options have been analysed: a) the effects of trees in urban areas and $b$ ) the modification by wind speed (Fig. 3), based on the assumption that in urban structures the parameters modified most are radiation fluxes (primarily by trees and buildings, here expressed by Tmrt) and wind speed. These two parameters are also the possibilities that can easily be modified or changed by urban planning measures.

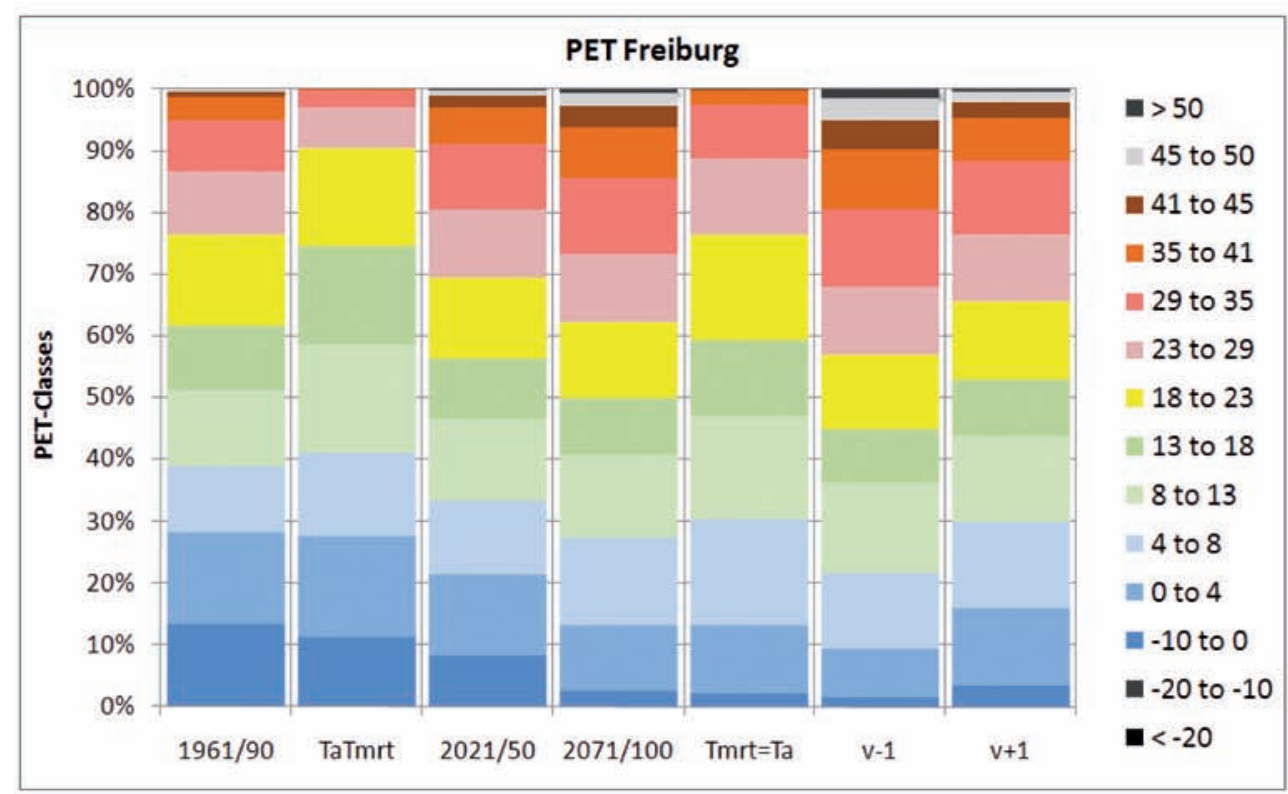

Fig. 3: PET for Freiburg for Different Periods by Modifying Radiation and Wind Conditions Based on REMO-Simulations and the A1B IPCC Scenario.

sidered month etc. Considering the second row in Fig. 1, heat stress occurs from June to September with an average frequency between $20 \%$ and $40 \%$, meaning that approx. 6 to 12 days are characterized by heat stress. In Figure 1 the CTIS for Freiburg for the period 1961-1990 is presented as an example. More detailed information concerning thermal comfort, cold and heat stress can be derived analysing the thermal bioclimate conditions based also on frequencies as shown in Fig. 2, where PETconditions are shown in 10-day intervals in terms of frequencies of thermal stress classes including the annual mean and extremes in amount of days of occurrence and providing information for a destination analysis.

Additional information based on regional climate modelling can determine possible changes and, in discussion with specific scientific disciplines, actions can be taken. In addition, specific kinds of
Based on the assumption that air temperature is in the same level like mean radiant temperature (Tmrt $=T a$, more or less shady conditions) changes in heat stress are very high. If wind speed is modified by an increase of $1 \mathrm{~m} / \mathrm{s}$, days with heat stress will decrease compared to original PET conditions. Possible changes of heat stress days $\left(\mathrm{PET}>35^{\circ} \mathrm{C}\right.$ ) are shown in the $\mathrm{A} 1 \mathrm{~B}$ scenario. If radiation is reduced (here Tmrt $=\mathrm{Ta}$ ), heat stress days will decrease significantly until the end of the century (for $\mathrm{A}_{1} \mathrm{~B}$ ). If wind is reduced, heat stress days increase in all cases, with highest changes for $A 1 B$ for the period $2071-2100$ and an amount of 30 days. If wind speed is increased by only $1 \mathrm{~m} / \mathrm{s}$, a decrease of days with heat stress is indicated. The present analysis for Freiburg shows that, in general, days with heat stress will increase and days with cold stress will decrease in expected future climate conditions. The changes are much bigger when radiation fluxes are modified (here Ta=Tmrt). These changes 
can be arranged by planting specific and relevant vegetation types that produce shade in summer and allow short wave radiation to reach the surface or the areas where humans spend their time in winter. If wind is modified, the result is not as effective, but it is relevant to know that increased wind speed in complex structures can reduce thermal conditions of hot conditions.

Based on results such as these, tourists, the tourism industry, health resorts and authorities can be prepared or protected in order to avoid negative developments in the economic sectors of tourism and health.

\section{References}

De Freitas, C. R. (2003): Tourism Climatology: Evaluating Environmental Information for Decision Making and Business Planning in the Recreation and Tourism Sector. International Journal of Biometeorology 48: 45-54.

Matzarakis, A. (2006): Weather and Climate Related Information for Tourism. Tourism and Hospitality Planning \& Development 3/2: 99-115.

Matzarakis, A. (2007): Assessment Method for Climate and Tourism Based on Daily Data. In: Matzarakis, A., C. R. de Freitas \& D. Scott (eds.): Developments in Tourism Climatology. Commission on Climate, Tourism and Recreation, International Society of Biometeorology. Freiburg: 52-58.

Matzarakis, A., A. Möller, E. Kreilkamp et al. (2009): Anpassungsstrategien zum Klimawandel touristischer Pilotdestinationen in Küsten- und Mittelgebirgsregionen. In: Mahammadzadeh, M., H. Biebeler \& H. Bardt (eds.): Klimaschutz und Anpassung an die Klimafolgen. Institut der Deutschen Wirtschaft Köln Medien GmbH, Köln: 253-262.

Scott, D., C. R. de Freitas \& A. Matzarakis (2009): Adaptation in the Tourism and Recreation Sector. In: McGregor, G. R., I. Burton \& K. Ebi (eds.) (2009): Biometeorology for Adaptation to Climate Variability and Change. Springer, Dordrecht: 171-194.

More infos: http://www.urbanclimate.net/climtour and on the website of the Commission on Climate, Tourism and Recreation of the International Society of Biometeorology (http://www.urbanclimate.net/cctr). 


\title{
Energy Systems of the Future: New Perspectives for Efficiency and Renewables
}

\author{
Stefan P. Schleicher
}

\section{The Need for Change}

Is the carrying capacity of planet earth able to maintain economic activities for countries like China and India in the same way as we are used to in Europe or the United States? There is increasing evidence that this will just not be possible.

An example is the use of crude oil. If these two countries, which account for roughly about a third of the world's population, would want to use the same amount of this energy source per capita as we do in Europe, we would need to double the world production of crude oil. None of the oil-producing companies expect that this could become feasible. In fact, we are now discussing the issue of peak oil, the moment when global oil production will have reached the historical peak of production. This explains the current rush for the last available oil fields, with China being willing to pay almost any price. Similar peak phenomena can be observed concerning water, grain, fish and a long list of minerals.

Obviously the big challenge is to develop an economic paradigm that can be globalized. This is obviously not true for the current paradigm that dominates our perception of economic welfare and the corresponding economic activities in the old industrial countries. But is there a way out?

There is not only a race for the last reserves of precious fossil energies such as oil and gas, but also a race for a credible shift of the currently dominant economic paradigm. Apart from uncertainties concerning reserves, the new map of geopolitics, the call for a carbon-constraint economy, or new demands by emerging industrialized countries in Asia, there is an emerging consensus that in order to provide more wealth to more people we need to fundamentally rethink the way we organize economic activities.
Again the use of crude oil serves as an illuminating example. The still dominant use of oil is determined by its energetic functionality. Major advances in materials science, however, have been made concerning the material functionality of oil. Fibre-enforced polymers can customize the physical properties of every cubic millimeter of a structure. They do not only replace, but outperform concrete and steel in many applications. These polymers can be produced from oil, but also from recycled plastics. In a next stage of technological development industrial polymers will be produced from plantbased materials.

Without being able to suggest definitive answers, we want to make two contributions to these emerging discussions. First, we propose a conceptual framework that is adequate for analyzing this complex issue since we argue that it is more important to formulate the right questions before giving premature answers. Second, having realized the importance of this issue, we put forward a framework for restructuring our energy system based on already emerging technologies, concepts and examples.

\section{Shifting the Paradigm: From Products to Functionalities and Services}

Our perceptions of economic activity and the related issues of economic welfare have been shaped by the mainstream paradigm that is visualized in figure 1: The focus is on the products (material and immaterial) for which we need human and energetic resources. Oil and other hydrocarbons serve in this paradigm mainly as sources for energy and may be replaced by renewables. 


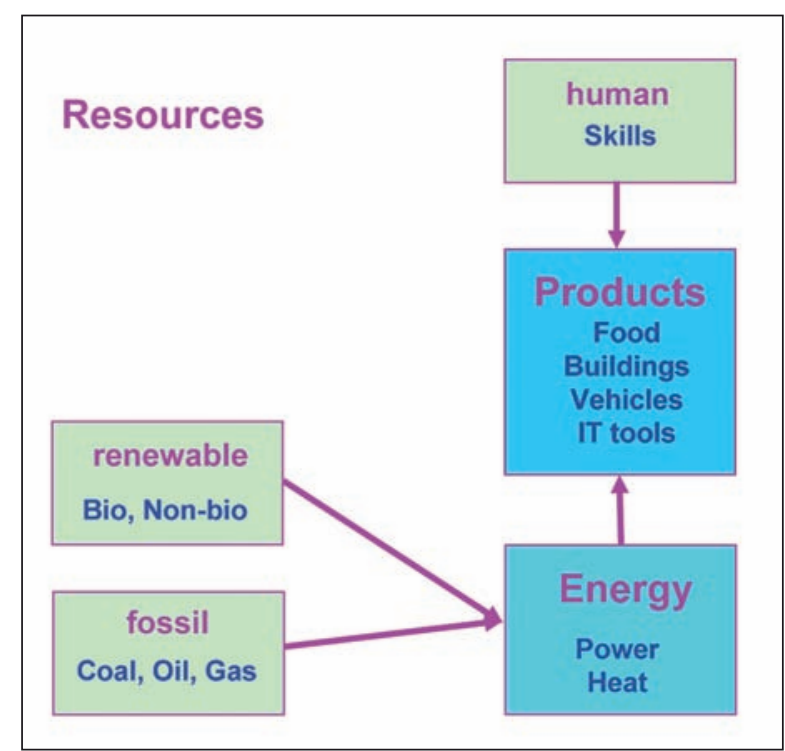

Fig. 1: Mainstream Paradigm of Economic Activity.

The limits of this mainstream paradigm are revealed if we look at what we coin the comprehensive paradigm of economic activity as indicated in figure 2 with a number of extensions and distinctive differences: First, the emphasis is not on products, but on the functionality they provide for nutrition, housing, mobility and knowledge by providing all kinds of services, the most important ones being thermal and mechanical. Not gross domestic products, the conventional measure for measuring the volume of products, are the policy target but welfare expressed in the availability of the functionalities provided by the products. Second, fossil and renewable resources serve not only energetic but also material purposes. This has far-reaching implications, since it calls into question the one-step energetic use of both petroleum-based and biomass-based resources in contrast to the option of a multi-step product cycle that is terminated only at the very end by using its energy content. Third, applications with a high use of energy can widely be replaced by more energy-efficient products, as, for example, vehicles and buildings with a much higher energy productivity.

These distinguishing features of the comprehensive paradigm are easily applicable to housing. The product "buildings" is needed to provide the functionality of housing with the corresponding thermal services. How much energy is needed depends, however, to a large extent on the thermal quality of the product "buildings" and the state of the natural resource describing the climate zone the building is located in. Austria, for example, has become a technology leader for advanced building designs. Compared to traditional buildings, new buildings typically cut energy consumption by the factor of four. Even more modern buildings achieve even a factor of ten and pilot projects reveal that currently available technologies enable building designs that harvest more energy than they actually need themselves and are thus called plus-energy buildings which we may coin hyper buildings. Similarly we can discuss advanced car designs that have become known as hyper cars. Their specific design characteristics are extremely light-weight structures based on fiber-reinforced polymers and powered by electricity.

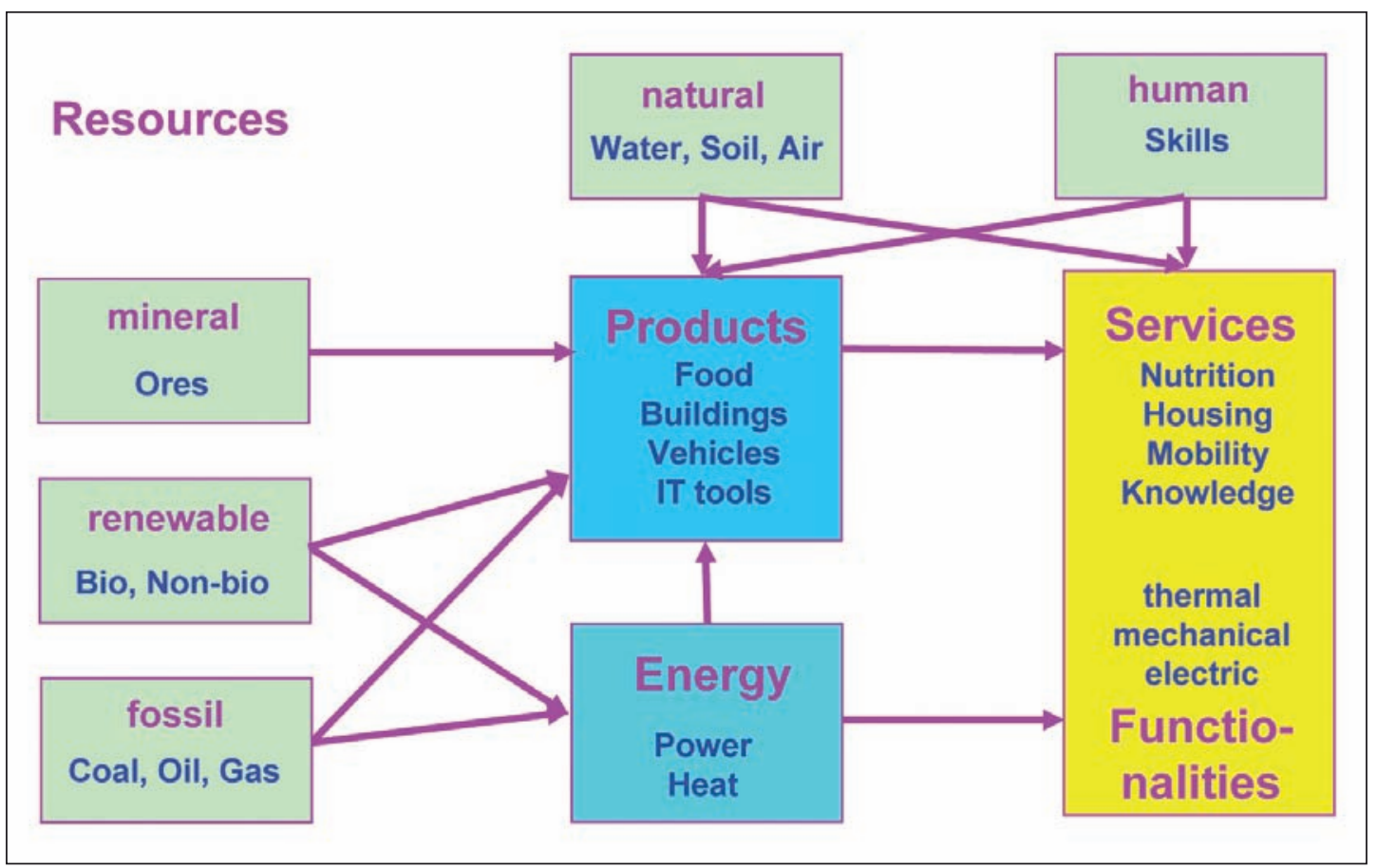

Fig. 2: Comprehensive Paradigm of Economic Activity. 


\section{The Emerging New Energy Paradigm}

We indicated that our current economic paradigm is in a transitional phase. This is particularly visible in the discussions about revising our current accounting systems. The so-called Stiglitz Commission on the Measurement of Economic Performance and Social Progress (Stiglitz et al. 2009) is considered a major step in the development of an economic paradigm that is more credible and constructive than the current mainstream one.

The implications for understanding and re-designing our energy systems are obvious and require a fundamental change in the way we decide about energy both on the level of consumers and companies and on all levels of policy making. In a nutshell this paradigm shift requires a Copernican revolution that takes us away from the current focus on energy flows to the energy services that are relevant for our well-being.

This can be visualized in figure 3 by looking at the cascading structure of an energy system. At the top layer we discover energy services of the following types:

- thermal energy services for maintaining buildings at comfortable temperatures and enabling heat-related production processes,

- mechanical energy services for providing mobile or stationary services in all kinds of machinery, and - specific electric energy services needed for lighting and electronics.

The middle layer of the energy system is composed of the energy flows that are metered in households and companies and which comprises final energy for

- heating and cooling in buildings and production,

- fuels for stationary and mobile engines, and

- electricity for machinery, lighting, electronics and electro-chemical processes.

The amount of final energy is determined both by the amount of energy services needed and the qualities of the corresponding application technologies as well as the thermal structure of buildings, the efficiency of machinery and appliances.

The lowest layer of the energy system concerns the primary energy flows as

- fossil energy (coal, crude oil, natural gas),

- renewable energies (thermal and PV solar, wind, hydro, biomass), and

- uranium for nuclear transformation processes.

The Copernican revolution of our energy system consists in the upside-down shift in the analyses of our energy systems. Instead of asking where we can get more primary energy from we emphasize the role of energy services as the starting point and ask about
- the amount of energy services needed by trying to avoid redundancies and

- the adequate application technologies that provide these services with highest energy productivities.

Only afterwards we look at the amount of primary energy needed by

- checking the availability of renewable and nonrenewable primary energy and

- using transformation technologies with highest efficiencies.

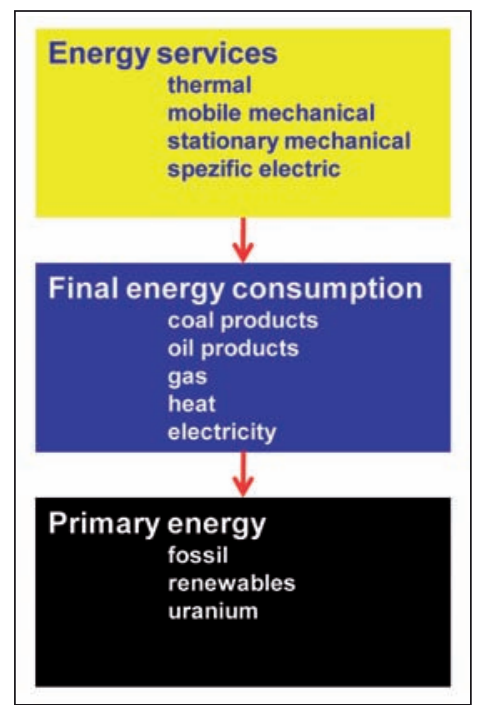

Fig. 3: The Energy Cascade.

\section{Envisaging the Transformation}

A number of operational concepts have emerged from this new perspective of energy systems. An outstanding example is the vision of a 2,000 watt society that originates from the Swiss Federal Institute of Technology in Zurich. This refers to the current world average energy use which is extremely unevenly distributed since it ranges from 300 watts in Bangladesh to 6,000 watts in Western Europe and 12,000 watts in the United States. In a 2,000 watt society the old industrialized economies would be able to maintain their current standard of living and enable the currently developing economies to catch up without increasing total global energy consumption. The technologies that enable such a transition are either already available or in a state of $R \& D$ which will make them available within a few years if enough efforts are made.

Similar concepts have been suggested for the United States by Lovins et al. (2004) and McKinsey \& Company (2010). On a global scale these paradigm shifts received high attention by the technology wedges approach proposed by Pacala and Socolow (2004). 


\section{0}

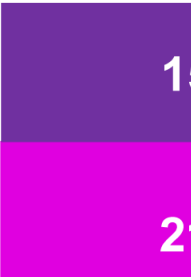

15 losses

21

low temperatures

2050

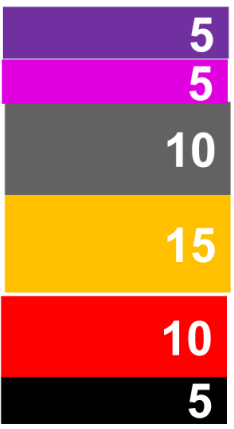

Renewables

9

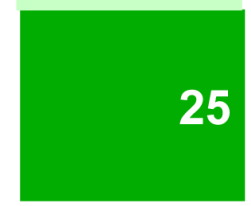

\section{high temperatures}

10 lighting, elextrinics, motors

9 non-energetic use

Fig. 4: The Energy Transition.

The common framework for all of these innovative concepts is the focus on the use of energy. The typical distribution of energy is indicated in figure 4 which stems from Austria but is representative of most other industrialized countries. The current energy flows in 2010 are scaled to 100. Given our present knowledge about the availability of technologies this could be the transition process up to 2050:

$-15 \%$ of energy (a rather low number in Austria) is lost in the thermal transformation process and in distribution. This number could be cut down by a factor of three, if we apply currently available highefficiency cogeneration technologies.

$-21 \%$ of energy is used for low-temperature heating in buildings. Currently available technologies could reduce these energy flows at least by a factor of four without compromising the thermal services.

$-28 \%$ of energy is used for mobility in rather inefficient combustion engines. A new generation of fully electric powered vehicles could improve the energy efficiency at least by a factor of four.

- The remaining energy needs are rather modest, namely $17 \%$ for high temperatures in production, only $10 \%$ for lighting, electronics and electric motors, and $9 \%$ for non-energetic use in production processes such as for iron and steel.

Given these insights into current energy use and the potentials for improvements it is very reason- able to postulate at least a $50 \%$ reduction of energy flows by 2050 or even more without sacrificing desired energy services. These, obviously, are the qualities of the energy systems to come:

- low energy by switching to high-efficiency application and transformation technologies,

- low carbon by phasing out fossil energy and stepping up renewables, and

- low distance by discovering the potential of locally available energy sources from solar, wind, hydro and biomass power.

\section{References}

Lovins, A. B. et al. (2004): Winning the Oil Endgame. Innovation for Profits, Jobs and Security. Earthscan, London.

McKinsey \& Company (2010): Energy Efficiency: A Compelling Global Resource. www.mckinsey.com.

Pacala, S. \& R. Socolow (2004): Stabilization Wedges: Solving the Climate Problem for the Next 50 Years with Current Technologies. Science 305: 968-972.

Paul Scherrer Institut (2007): The 2000 Watt Society: Standard or Guidepost? Energie-Spiegel, April 2007. http://gabe.web.psi.ch/energie-spiegel/

Stiglitz, J. E., A. Sen \& J.-P. Fitoussi (2009): Report by the Commission on the Measurement of Economic Performance and Social Progress. www.stiglitz-sen-fitoussi.fr 


\title{
Action Plan of the Alpine Convention for Climate in the Alps: Climate Neutral Alps by 2050 - Must or Utopia?
}

\author{
Blanka Bartol, Patricia Quillacq*
}

\section{Introduction: Changing Climate, Modified Alpine Environment}

Pictures of high Alpine tourist resorts with green or grey mountains in the background look like funny caricatures of skiing grounds. But the picture is real: many winter resorts have begun to suffer from a rising snowline to higher altitudes. Other phenomena are rapid changes in territories such as mountains where regular transformation occurs in long-term periods.

Scientific evidence proves that the Alps are among the most vulnerable areas to climate change in Europe. The main reason is the increase of temperature of around $+2^{\circ} \mathrm{C}$ between the late 19th and early $215 t$ century, which is twice the temperature increase in the northern hemisphere and leads to the melting of glaciers, climbing of the snowline, changes in the run-off regime of rivers and general water resource availability (Auer et al. 2007).

\section{Impacts of Climate Change}

Since most of the major European rivers have their water hinterlands in the Alps, the mountains are crucial for water accumulation and water supply of lower European areas and lakes. But changes in the Alpine ecosystems induced by warming climate have also great impacts on Alpine society itself. Tourism in the Alps for example, which is a key contributor to the economy of Alpine countries, will be seriously influenced due to snow reliability of Alpine ski areas in the future. The impacts on the winter tourism economy were profoundly analyzed in an OECD cross-country study, also suggesting some policy responses. Another problem is the increased vulnerability of regions to natural hazards, such as flooding. The problem was explained in the second report on the state of the Alps entitled "Water and Water Management Issues" (see Alpine Convention, Second Report): "Especially in the last years, natural hazards with great damage potential have occurred very often and intensely. The Alpine Countries were forced to increase their annual investments because there are more complex solutions to be developed for the flood control systems."

\section{An Institutional Response to the Changing Climate in the Alps: the Action Plan}

On the basis of the evidence mentioned above ministers of the contracting parties to the Alpine Convention decided to take some joint steps: they prepared the Action Plan as a framework for more focused actions in the field of climate change. The Action Plan was adopted at the X. Alpine Conference in Evian, France, with a vision to make the Alps an exemplary region for mitigation and adaptation to climate change. The 24 objectives specific to Alpine territory were defined in nine strategic areas (Spatial and Land Planning, Energy for Heating and Cooling, Transport, Tourism, Mountain Forests, Biodiversity, Water and Water Resources, Mountain Agriculture, Research and Awareness Raising). Although Alpine countries conduct numerous activities in the field of mitigation and adaptation to climate change in their national frameworks, the agreement on common objectives for specific geographical areas means a unique opportunity for

\footnotetext{
* The views contained in the article are those of the authors and do not necessarily reflect the position of the Permanent Secretariat of the Alpine Convention.
} 
achieving synergies in combating climate change in the Alps since joint actions can have more effect than single efforts. That can be realized by a closer cooperation of the Permanent Secretariat, the contracting parties, the observers to the Alpine Convention, its platforms and working groups and other actors, such as regional and local communities.

After two years of implementation of the Action Plan and ministerial decisions, the XI. Alpine Conference, which will take place at Brdo near Kranj, Slovenia, in March 2011, will decide on further steps and directions in the framework of Alpine climate actions. pine Action Plan was also printed in the form of flyers, available to the broader public and offering quick and condensed information about the Action Plan.

The Slovenian Presidency of the Alpine Convention, whose task it was to initiate the implementation of the Climate Action Plan after its adoption in 2009, organized two thematic seminars in the framework of Permanent Committee meetings. National and regional climate mitigation and adaptation activities and projects were presented and discussed. The presented activities prove, as Mr. Jernej Stritih, Director of the Slovenian Govern-

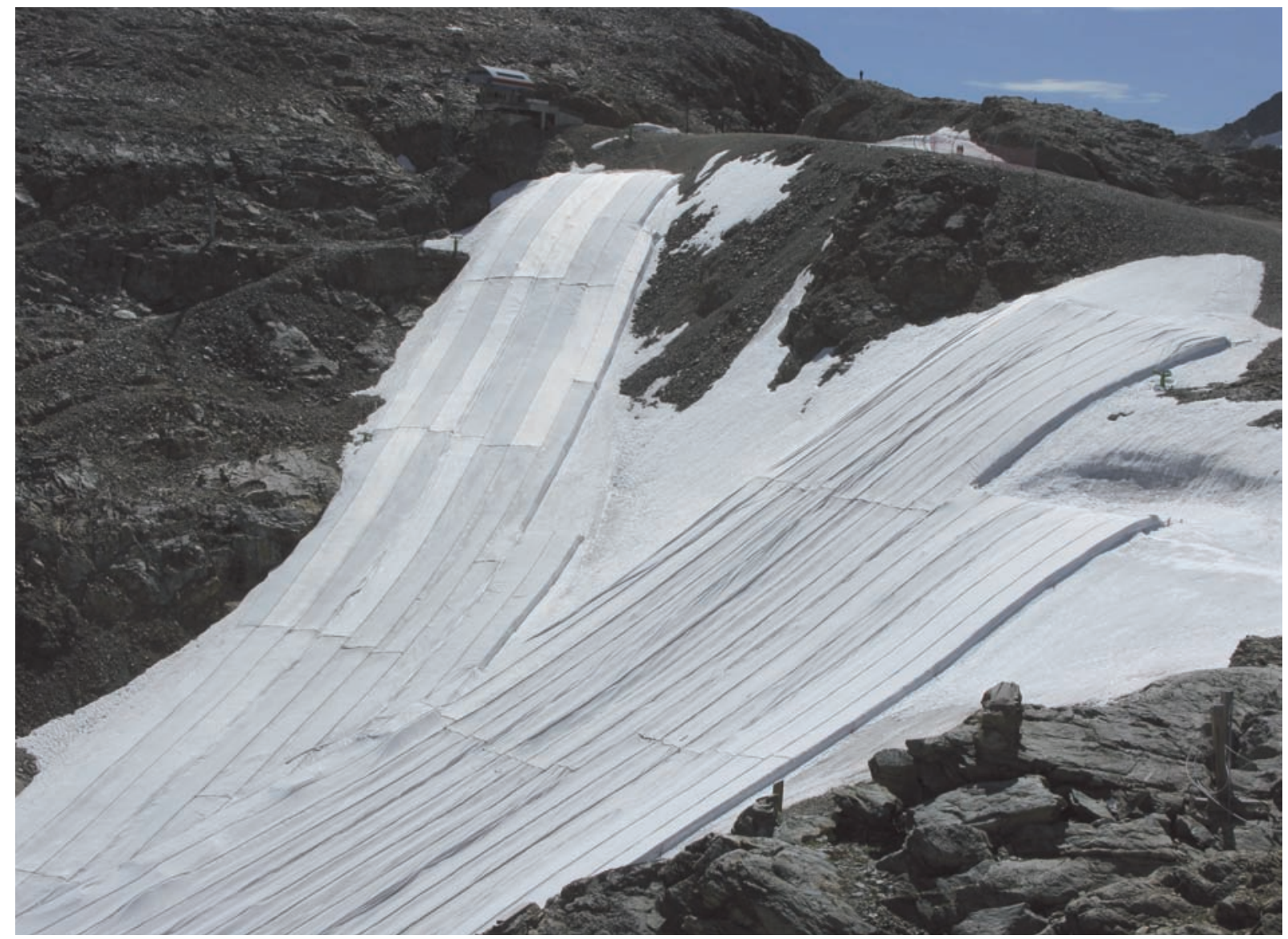

Fig.: Blanketing the Bernina Group Glacier in Summer - Adaptation to Climate Change Impact.

Source: Permanent Secretariat of the Alpine Convention, July 2010.

\section{Steps Towards the Implementation of the Action Plan}

One of the very first steps was the establishment of the internet portal (see http://www.alpconv. org) by the Permanent Secretariat of the Alpine Convention (PSAC), an information portal on the climate whose purpose is to communicate the Action Plan and to present latest findings about climate change, information on labels and certification, funding and financing and an overview on good practices. The shorter version of the Al- mental Office for Climate Change has said, that the Alpine area is an important forerunner in mitigation and adaptation processes. The outcomes were summarized in the following messages:

- the role of different levels and institutions in mitigation and adaptation activities and their coordination is of utmost importance;

- motivation of different stakeholders for further improvements of current achievements is very high;

- mitigation and adaptation projects have not been explicitly categorized as expenses; 
- the major future challenge is to accelerate the implementation of measures, to start and spread pilot regional approaches to the whole Alpine area in order to help others to learn from gained experiences.

In Evian, the Alpine ministers also agreed on some common future projects that are carried out by the Alpine working groups and platforms. The water platform, for example, lead jointly by Austria and Switzerland, works on preparing the guidelines for use of water for energy generation in light of the conflicting public interests of furthering renewable energy sources and an ecologically and societal sound promotion of hydropower; the platform will also prepare the assessment of the water management plans for the Alps from an adaptation point of view. The Natural Hazards Platform (PLANALP) was asked to document impacts of climate change on natural disasters. Liechtenstein prepared the award contest for sustainable building and renovation in the Alps.

\section{The Alps Climate Neutral: an Ambitious Yet Complex Project to Develop}

In Evian, the ministers also decided to conduct a study on the possibility for the Alps to become a carbon neutral area by 2050.

Carbon neutrality and climate neutrality are as much political goals for communities aiming towards a low-carbon lifestyle as scientific concepts. Indeed, when talking about carbon neutrality or climate neutrality, we are referring to the objective of reducing the emission of gases that have an impact on the climate, based on scientific information. Not only the issue of which gases shall be reduced must be considered, but also how much we can reduce, and how. If we understand from the beginning that climate neutrality contains these three dimensions, it is easier to understand why climate neutrality has different meanings in different countries and organizations, based on a variety of criteria, and different scientific assessments.

From the climate neutrality perspective Alpine regions do not have the same departure point, so setting objectives for becoming carbon/climate neutral for one Alpine region might mean something else than for the other. For example, this occurs when comparing highly industrialized regions in the Italian Alps and Alpine ecosystems in the Alpine Convention perimeter in Germany.

The first step in the carbon/climate neutrality issue was enabled by the German Ministry of the Environment which conducted the pre-feasibility study delivered by the Wuppertal Institut (Wuppertal Institut 2009). It establishes important departing points:
- There is an estimation that 100 million tons of $\mathrm{CO}_{2}$ are emitted annually in the Alps, representing an emission per capita of 7.4 tons/year (but the figures could hit higher if energy needed for manufacture and transport of goods brought into the Alps from outside is added).

- Ideally, the objective of turning towards a "climate neutral" society in the Alps should endorse the highest standards of GHG emissions reduction, and the minimum to reach for should be the reduction of emissions that supports the scenario of $2^{\circ} \mathrm{C}$ global temperature maximum increase, endorsed by the European Union. To achieve the stabilization of global temperatures at that level, most studies indicate that the average emission of a citizen in the world should be 2 tons of $\mathrm{CO}_{2} /$ year.

- Climate neutrality does not refer only to $\mathrm{CO}_{2}$ emissions, but shall encompass all greenhouse gas emissions.

- Climate neutrality targets within the context of the Alps could be better achieved through a sectoral approach. Three main areas of actions have been identified (with 3 sub-sectors):

1. Energy (including Buildings and Constructions, Energy, Transports),

2. Main business sectors (including Tourism, Land Use and Agriculture, Other Industries, Services and Trade),

3. Cross-cutting areas (Scenarios and Visions for Future Energy Uses, Spatial Planning, Institutions).

The problem of the definition for each "cluster" remains, in particular for the cross-cutting areas. The draft project outline for a possible transnational territorial cooperation project has been prepared by the Wuppertal Institut, and is developed further by the Slovenian Governmental Office for Climate Change in order to test the proposals of the pre-study in the regions, using the sector approach and establishing the knowledge and experience network exchange. The problem of neutrality has been very well summarized in the project outline by pointing out: "The preparatory work on the definition of 'climate neutrality' and defining the scope and boundaries of the emissions inventory formed the main content of the pre-study. (...) A final definition for the Alpine region is still pending". Moving from that point, it suggests that "the definition of climate neutrality should meet certain criteria in each of the nine thematic clusters. At the same time, a certain flexibility is needed with regard to specific circumstances in the Alpine region, data availability and local stakeholders powers to act".

Looking at international activities in the field of climate neutrality we should refer to the UNEP's recent publication on the concept of climate neutrality "Kick the Habit" (see United Nations Environment Programme). It acknowledges the huge gap 
between the current situation and a climate neutral future, but underlines that the "gulf is not uncrossable" and pinpoints the gains that can be made on that path. The publication provides answers for individuals, companies, corporations, cities and countries willing to start changing. The term climate neutrality is used in the book "to mean living in a way which produces no net greenhouse gas (GHG) emissions. This should be achieved by reducing your own GHG emissions as much as possible, and using carbon offsets to neutralize the remaining emissions."

Therefore, although the UNEP considers that climate neutrality should mean for a community not to produce "net GHG" emissions, there is not a general timeline to achieve this, nor one single solution. By doing so, the UNEP approach transforms the general objective of climate neutrality into a process by which cities, regions, countries and organizations set for themselves a path, method and timelines to achieve such an objective. The UNEP has therefore created a global "Climate Neutral Network" (see http://www.unep.org). The Principality of Monaco is already part of this CN Net.

It seems that with the climate change challenges, the world needs some new policy paradigms such as carbon/climate neutrality or resilience to climate change which would mobilize new ideas, shape societal and individual behaviours on their way towards new dimensions of sustainable development concepts. For the Alps, setting right targets is extremely important while some issues still remain open, such as:

- What should be the focus of our future policies in the Alps: climate neutrality or resilience to climate change?

- How can the targets be set and the progress monitored?

- What kind of governance mechanisms and policy support are needed for the implementation of climate neutrality/resilience to climate change?

\section{References:}

http://www.alpconv.org/climate/index_en.htm

http://www.unep.org/ClimateNeutral/Default.aspx?tabid=709

Alpine Convention, Action Plan on Climate Change in

Alps, 2009 http://www.alpconv.org/NR/rdonlyres/193D7A9EOF5E-475D-A48D-E3276F11D292/o/AC X_B6 en_new_fin.pdf

Alpine Convention, Second Report on the State of the Alps "Water and Water Management Issues"

http://www.alpconv.org/soia/soiao3_b_en.htm

Auer, I., R. Böhm, A. Jurkovic et al. (2007): HISTALP - Historical Instrumental Climatological Surface Time Series of the Greater Alpine Region 1760-2003. International Journal of Climatology 27: 17-46.

European Environment Agency (EEA): Regional Climate Change and Adaptation - The Alps Facing the Challenge of Changing Water Resources, EEA Report 8/2009 http://www.eea.europa.eu/publications/alps-climatechange-and-adaptation-2009

Organisation for Economic Co-operation and Development (OECD): Climate Change in the European Alps: Adapting Winter Tourism and Natural Hazards Management, 2007 http://www.oecd.org/document/45/o,3343,en_2649_ 34361_37819437_1_1_1_1,oo.html

United Nations Environment Programme (UNEP), Kick the Habit. A UN Guide to Climate Neutrality

http://www.unep.org/publications/ebooks/kick-the-habit/

Wuppertal Institut für Klima, Umwelt und Energie $\mathrm{GmbH}$, Pre-Study, Climate Neutral Alpine Region 2050, 13 October 2009. 


\title{
Workshops
}

\section{2/1 Adaptation to Climate Change in the Alps (Alpine Space Projects)}

\author{
Presentation: Marion Damm \\ Input: Anton Loipersberger, Wolfgang Lexer, Volkmar Mair, Daniela Hohenwallner, Lucia Brusegan
}

\section{General Information}

The Alps have undergone an exceptionally high temperature increase of around $+2^{\circ} \mathrm{C}$ between the late 19th and early 21st century, more than twice the rate of average warming of the Northern hemisphere, leading to widespread melting of glaciers and permafrost soils, climbing of the snow line, changes in precipitation patterns and run-off regimes of rivers, etc. (Auer et al. 2007). Already comparatively minor climatic changes can have significant impacts on the natural and socio-economic systems of the Alps. The results of ClimChAlp (2008) have shown that adaptation in various sectors like housing, tourism, water management and spatial planning requires sound data, a strong risk management and consistent strategies and response measures. A comprehensive decision basis is needed that enables policy-makers to establish a regulatory framework for climate-proof measures and helps to assess and communicate risks throughout the Alpine Space.

The European Territorial Cooperation Alpine Space Programme 2007-2013 is co-funding a number of projects which are concerned with the topic of adaptation to the consequences of climate change in the Alpine Space. The Programme strives for transnational cooperation between the Alpine Space member states and consequently acknowledges the need for knowledge transfer and collaborations across national and regional borders.

This workshop gathers experts, including from the running Alpine Space project communities, that are concerned with issues of climate change impacts and adaptation in the Alps.

\section{Concept and Objective of the Workshop}

The workshop is expected to outline ongoing work, highlight interim research findings and identify crucial starting points for action in adaption to climate change. It will specifically address the issue of developing strategies for climate-proofing of sectors such as tourism, water management, spatial planning and disaster control. Focusing on review and discussion of different approaches, the workshop aims to highlight current achievements, to identify challenges and to articulate response options. Moreover, contributors will demonstrate how interfaces and synergies between the interdisciplinary axes of the projects can be exploited to ensure the development of coherent Alpine adaptation strategies.

Five presentations will be given by representatives from the projects AdaptAlp, CLISP, PermaNet, ClimAlpTour and Alp-Water-Scarce. Afterwards, the opportunity for in-depth discussions will be given.

The workshop addresses all experts, scientists and decision-makers which are interested or engaged in the field of adaptation.

\section{Project Presentations}

\section{AdaptAlp (Anton Loipersberger)}

Climate change is to a large extent constituted of increasing temperatures and changed precipitation patterns. Any change of these critical factors has implications on the frequency and extent of natural hazards. The uncertainties and the increase of natural hazards due to the impacts of climate change require concerted management in the Alpine Space. AdaptAlp aims to (1) improve information on the potential impact of climate change especially on small-scale level, (2) to evaluate and harmonize different methods of risk assessment, hazard mapping and risk management in the Alpine environment, (3) to identify good practice methods and transfer best practice experiences into adaptation measures in model regions, and finally (4) to reduce risk by raising awareness among local stakeholders and responsible politicians. One central theme is a pragmatic, transnational approach to improve risk 
prevention and management. Based on good examples, case studies, workshops and expert hearings the transnational network will open an integrated risk dialogue to identify the most effective methods. In several model regions across the Alpine Space the project partners work together with decision-makers at the local level to enhance risk communication and risk management. The experiences made in the model regions will show how to successfully implement adaptation measures in hazard-prone areas.

\section{CLISP (Wolfgang Lexer)}

Climate change will affect spatial development, including land use, socio-economic activities and lifesustaining ecosystem services, in the Alpine Space more severely than in other European regions. Doing nothing will increase vulnerability of Alpine regions and municipalities, and therewith damages and costs. Spatial planning has major steering capacity in accomplishing adaptation, containing vulnerability and increasing resilience.

CLISP aims at preventing, reducing and mitigating climate-change related spatial conflicts, vulnerability of spatial development and spatial structures to adverse climate change impacts, and consequential damages and costs. As climate change adaptation, including an integrated approach to adaptation and mitigation issues, is still a novel field for spatial planning policy and administration, CLISP is to be regarded as a strategic pilot project. The project intends to contribute to sustainable, climate-proof spatial planning and territorial development in the Alpine Space. In the presentation, a transferable framework for regional vulnerability assessment will be presented and selected results from assessing key vulnerabilities of spatial development in model regions will be highlighted. Based on an evaluation of the adaptation capacities of spatial planning systems, the potentials and constraints of existing spatial planning instruments in coping with adverse climate change impacts will be identified, and resulting challenges for climate-proof planning will be discussed with participants.

\section{PermaNET (Volkmar Mair)}

Permafrost is highly sensitive to climatic changes. Permafrost degradation and related natural hazards affect traffic routes, tourism areas, settlements and infrastructures. However, data on permafrost is spatially inconsistent and a map of the distribution of permafrost in the entire Alpine Space does not exist. The overall objective of the PermaNET project is to make an important contribution to the mitigation of natural hazards that result from climate change impacts on Alpine permafrost. Through the creation of an Alpine-wide monitoring network and by developing a common strategy for dealing with permafrost related hazards, PermaNET contributes to sustainable development and the implementation of good governance practices. PermaNET will provide decision-makers and responsible authorities with the necessary decision bases and strategies to deal with permafrost related hazards. Gaps in the data of permafrost distribution will be closed and a continuous permafrost map and database for the entire Alpine Space will be produced. New and promising technologies will be tested and joint solutions for the adaptation of risk management practices will be explored.

\section{Alp-Water-Scarce (Carmen de Jong / Daniela Hohenwallner)}

It is expected that climate change will have a big impact on the water resources of the Alps. At least the southern part of the "Water Towers of Europe" is already affected by droughts and local water shortages. Furthermore, increasing anthropogenic water abstraction will exacerbate this problem of water scarcity in the area. To adapt and mitigate these problems Alp-Water-Scarce's long-term aim is to reinforce authorities and stakeholders to develop integrated and sustainable water management against water scarcity. On the short term, an early warning system against water shortage in the Alps will be created based on sound and integrated hydrological regional and sub basin models. Climate and anthropogenic scenarios are to be adapted and developed to enable prediction of future vulnerability to water scarcity. Special emphasis will be placed on the definition of optimal ecological flow of surface discharge and groundwater biotopes, supported by the selection and application of aquatic indicators and biodiversity change. Finally, the developed early warning system will be tested in some of the 23 pilot sites of the project. All actions within Alp-Water-Scarce are strongly supported by the Stakeholder Interaction Forum which will accompany the entire project and establish or extend an effective communication network.

\section{ClimAlpTour (Lucia Brusegan)}

Tourism is closely related to climate variations, especially in mountain regions, where without snow it is not possible to ski and therefore are heavily dependent on snow precipitations. What are the expected effects of an increase in temperature? How could climate change affect the economic and social system of the mountains? How is climate change affecting all-season tourism in the Alps?

The ClimAlpTour project focuses on the Alpine Space, where the effects of climate change could be stronger. Furthermore, the project considers winter tourism resorts as the focus of its studies. The main objective of the project is to make Alpine centres an interesting destination in all seasons and to 
increase their potential even if snow is lacking. 18 ClimAlpTour Partners from 6 Alpine countries are working together to find out concrete adaptation strategies that can be used by civil services and stakeholders to face this new situation and to go beyond the traditional vision of winter sports. Furthermore, partners wish to raise the consciousness among citizens, businessmen and, above all, policymakers on the possible changes of the climate, to identify the most appropriate strategies and to act on a timely base and on valid information. The project will deliver a powerful decision supporting system able to provide to all interested parties customized adaptation strategies based on infor- mation referring to every specific site: 23 model regions of the Alpine arch are studied and assisted to develop and apply tailored strategies to adapt to climate changes.

\section{References}

Auer, I., R. Böhm, A. Jurkovic et al. (2007): HISTALP - Historical Instrumental Climatological Surface Time Series of the Greater Alpine Region 1760-2003. International Journal of Climatology 27: 17-46.

ClimChAlp (2008): Impacts of Climate Change on Spatial Development and Economy: Synthesis and Model Region Studies. Extended Scientific Report of WP7 of the Interreg III B Alpine Space Project ClimChAlp.

\title{
2/2 Climate Neutral Development: Discussion of Expert Studies for Munich and for the Alps
}

\author{
Presentation: Stefan Lechtenböhmer, Johannes Venjakob \\ Input: Jernej Stritih, Stefan Lechtenböhmer
}

Managing climate change and reducing greenhouse gas emissions will be one of the main challenges for our society over the coming decades. This affects the social and infrastructural development of the whole Alpine region; high-density urban areas as well as rural territories.

At present no detailed data is available on greenhouse gas emissions or the resulting climate balance for the Alpine region. Estimates point to a current level of around 100 million tonnes of carbon dioxide emissions annually. In terms of the population in the Alps, this represents a per capita level of around 7.4 tonnes a year. Factoring in the energy needed for the manufacturing and transport of goods brought into the Alpine region from outside could put the figure significantly higher.

Furthermore, the latest findings of climate research indicate that the Alps are likely to experience significantly higher temperature increases than other parts of Europe.

The results of the Copenhagen Conference have made it plain that global warming is to be stabilised at a maximum of 2 degrees above pre-industrial levels. To achieve this aim, greenhouse gas emissions have to be reduced to a global mean of less than 2 tonnes per capita by the middle of this century. The faster this reduction is achieved, the more likely the warming can be limited to the target level. Comprehensive and substantiated strategies are needed to cope with these future developments and corresponding adaptation requirements.

It becomes apparent that there is an increasing demand to discuss concepts which help to find solutions for a sustainable future development of metropolises and rural regions in a climate neutral sense. The "Low Carbon Society" approach is a possible concept, which can be applied to encourage a systems change leading to a more climate neutral future, though it is not finally defined and clarified in all parts. For example there are different methods of balancing greenhouse gas emissions. Territorial approaches are conceivable as well as polluter-based principles. A common definition of climate neutrality is also missing. Furthermore, climate neutrality can be reached by top-down and bottom-up approaches.

The workshop addresses the question how to further substantiate the "Low Carbon Society" approach and how to apply it to the Alpine region. This discussion will take place in the context of the findings of two recent studies, investigating a possible low carbon future of the Alpine region and Munich in particular which will be presented within the workshop.

\section{The "Low Carbon Society" Concept from an Alpine Perspective (Jernej Stritih)}

Against the background of climate change, high vulnerability of the Alpine ecosystem, and the urgent demand for profound concepts identifying solutions, the X. Alpine Conference adopted its Climate Action Plan. It aims to make the Alps a model region for mitigating and adapting to climate change. At the same time, the Conference decided 
to conduct a study into "how the Alps can become climate neutral by 2050".

The study was accomplished in 2009 and discussed different approaches of balancing greenhouse gas emissions (Wuppertal Institut 2009). The main polluting sectors were identified and best practice concepts to reduce emissions were sketched. The preparatory work on the definition of the term "climate neutrality" and defining the scope and boundaries of the emissions inventory formed the main content of the study; a final definition for the Alpine region is still pending.

The next step is to demonstrate how existing know-how in methods of reducing $\mathrm{CO}_{2}$ emissions, many of which have already been implemented in pilot studies, can be applied throughout the Alpine region. Individual measures are known and have frequently been evaluated with regard to their reduction potential. However, the different reduction measures must be combined to achieve a high level of climate neutrality at the local level and throughout the region.

For this purpose, Slovenia as the present chair of the Alpine Convention is coordinating the preparation of an EU funded Alpine Space project. The main idea of the project is to integrate the existing good practices into integrated low carbon strategies in the pilot regions and secure a long term mechanism of multiplication of practices and results, so that these combined practices can be tailored to all regions in a common approach securing the final result of climate neutrality for the Alps.

\section{Sustainable Urban Infrastructure - Paths Towards a Carbon-Free Future (Stefan Lechtenböhmer)}

Sustainable low carbon societies are to be created on all levels - national, regional and local. For the conversion of our infrastructures, which are to a large extent determining anthropogenic GHG emissions, the urban level is decisive. Cities are now a home to more than $50 \%$ of the global population, but they are responsible for more than $70 \%$ of energy use and GHG emissions. And they play an important role in determining interactions between urban regions and their rural "Hinterland".

Metropolitan areas represent both a high concentration of causes and consequences of climate change and a high capacity for action. High economic capacity, concentration of scientific and technological as well as economic know-how and decision making competencies put them into the pole position to develop the way to more climate friendly and decarbonised lifestyles and economies.

Against this background Siemens and Wuppertal Institut conducted the study "Sustainable Urban Infrastructure: Munich - Roads towards a CarbonFree Future" (Siemens AG, Wuppertal Institut 2009; see also Lechtenböhmer 2009; Lechtenböhmer et al. 2009). While the city has survived almost 700 years mainly based on regional renewable sources, the last 150 years, like everywhere in the industrialised world, have seen a boosting use of fossil energy use. The resulting GHG emissions have risen to a current level of more than eight million tons of $\mathrm{CO}_{2}$ or 6.5 tons per capita. In our study we analysed two scenarios on how the city can become again

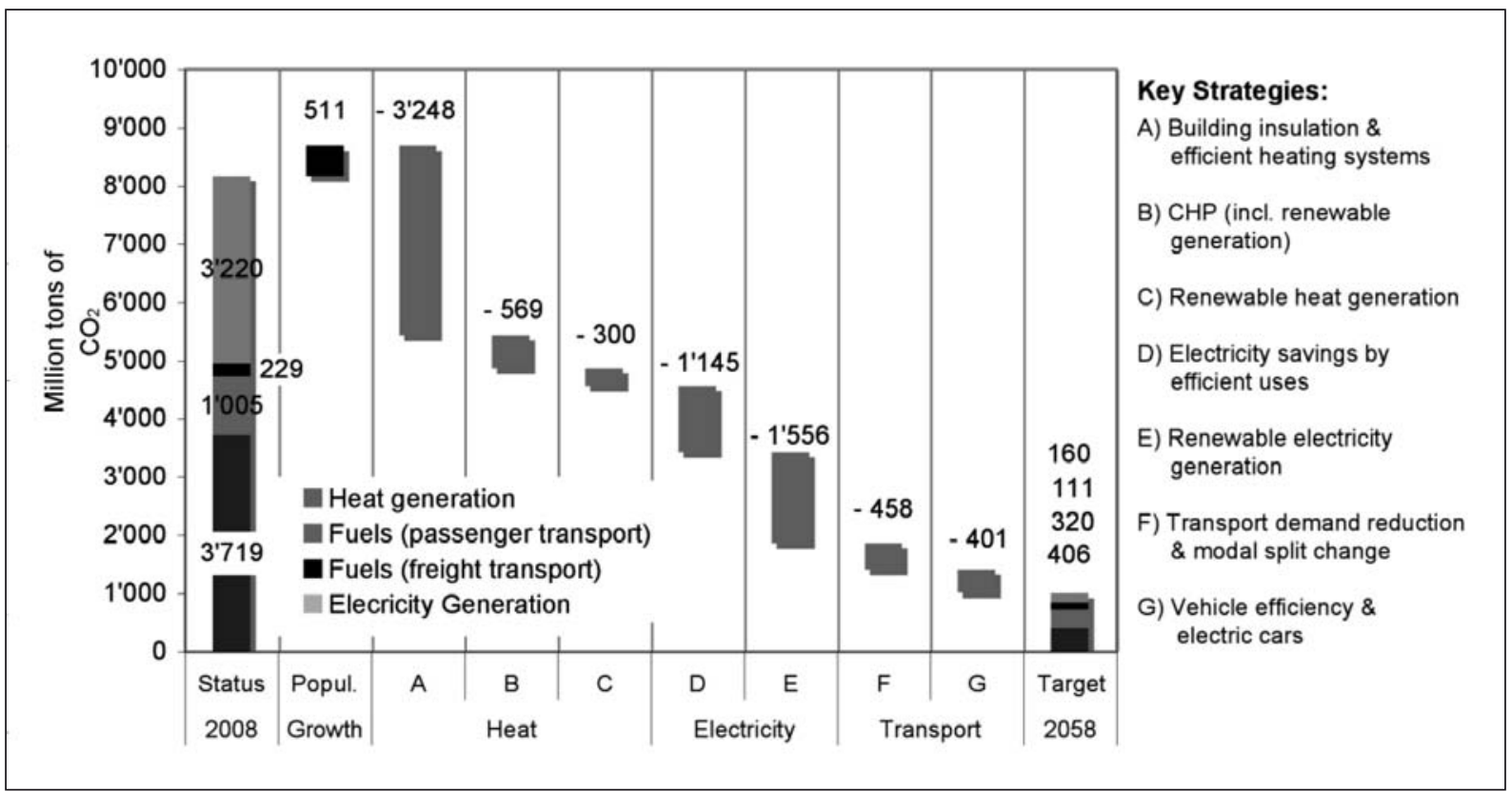

Key Strategies for Carbon Emission Reduction in Munich, 2058, Target Scenario.

Source: Lechtenböhmer (2009). 
almost fossil carbon-free by its gooth anniversary in 2058. The 7 key strategies for the city of Munich and their respective contribution to the $\mathrm{CO}_{2}$ emission reduction are given in the figure.

The results of the scenarios show that transforming a city into a virtually carbon-free urban environment will be a major challenge - one that can only be mastered if achieving this aim becomes top priority for all stakeholders within the city and around it: decision makers, utilities, urban planners and, particularly, investors and residents.

\section{References}

Lechtenböhmer, S. (2009): Paths to a Fossil $\mathrm{CO}_{2}$-Free $\mathrm{Mu}$ nich, in: Droege, P. (ed.): $100 \%$ Renewable. Energy Autonomy in Action. Earthscan, London: 87-92.

Lechtenböhmer, S. et al. (2009): Smart City - Bausteine auf dem Weg zu einer $\mathrm{CO}_{2}$-armen Stadt. Energiewirtschaftliche Tagesfragen 59/11: 8-13.

Siemens AG, Wuppertal Institut (2009): Sustainable Urban Infrastructure, Munich - Roads Toward a Carbon-Free Future. München.

Wuppertal Institut für Klima, Umwelt und Energie $\mathrm{GmbH}$ (2009): Climate Neutral Alpine Region 2050. Summary for Policy-Makers. Wuppertal.

\title{
2/3 Climate Response Measures - We Must Think One Step Ahead! Is Everything We Do in the Name of Climate Change Really Sustainable?!
}

\author{
Presentation: Wolfgang Pfefferkorn \\ Input: Bruno Abegg
}

\section{The Impacts of Climate Response Measures: a Topic Which Is Still Widely Neglected}

Dealing with climate change is still quite a young topic. Natural scientific approaches are still dominant. The key research areas are climate research as such (climate modelling, climate scenarios) and the impacts of climate change mainly on natural systems. Recently, the impacts of climate change on social systems have been of increasing interest. In addition, there has been a longer tradition to deal with mitigation measures than with adaptation measures.

In the cc.alps project (ongoing since 2008), the International Commission for the Protection of the Alps CIPRA has been working on a topic which is still widely neglected: the consequences and impacts not of climate change itself, but the consequences and impacts of climate response measures (CRM), i.e. of those measures which are taken to mitigate or to adapt to climate change. Until now, the impacts of these measures on nature and society, including the economy, have rarely been dealt with.

Between 2008 and 2010 CIPRA has investigated the impacts of about 300 already implemented climate response measures in the Alps. The results of this investigation can be summarised as follows:

- The main fields where climate response measures are taken are: energy, buildings and transport.

- Only $10 \%$ of the evaluated climate response measures can be classified as "very good" with regard to their impact on nature, society and economy.

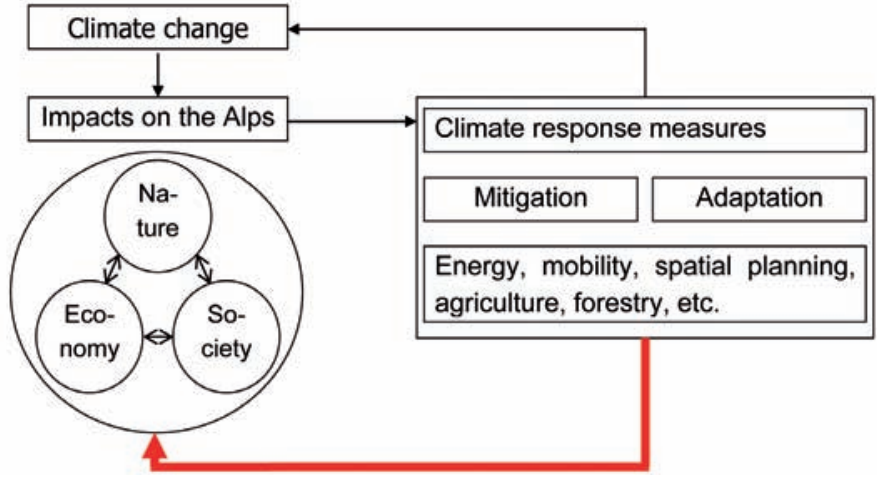

Tab. 1: Climate Change and Climate Response Measures.

- About $90 \%$ of the evaluated climate response measures have (some) negative side effects.

- Climate response measures often lead to target conflicts (e.g. between renewable energies and nature protection).

- About $90 \%$ of all evaluated measures are mitigation measures. Only $10 \%$ deal with adaptation.

- Many of the adaptation measures are often reactive and isolated. They are neither integrated nor prospective.

- Technical measures are mostly on local scale and easy to realise. On the other hand they often have only little impacts in regard to mitigation or adaptation.

- The strategic measures are mostly on regional scale, of a longer duration and well integrated. In general they have positive effects. 
We can say that the Alps are on the way but,

- we need more and better climate response measures.

- We need more awareness about the (negative) impacts of climate response measures and the related target conflicts.

- We need more exchange of experiences and transfer of knowledge among those who prepare or implement climate response measures.

\section{Workshop Aims}

- Discussing the impacts and main target conflicts related to climate response measures in the different activity fields,

- discussing experiences and possible solutions in the different Alpine countries,

- drawing conclusions for ongoing and future climate response measures.

\section{Workshop Agenda}

1. The workshop will start with an introduction by Bruno Abegg, the leading scientific expert of the CIRPA cc.alps project. He will present the experiences gained in cc.alps in regard to the issue of impacts and main target conflicts related to climate response measures.

2. In a second step, the participants will share their own experiences concerning impacts and target conflicts related to climate response measures and discuss possible solutions. According to the number of participants, this discussion will take place in the plenary or in small working groups.

3. In the third part of the workshop the participants will summarise conclusions and recommendations of how to develop and implement climate response measures which are in line with the principles of sustainable development. In addition they will work out proposals of how to improve "climate governance" in order to reduce and better deal with target conflicts related to climate response measures.

\section{Reference}

More information about cc.alps: http://www.cipra.org/en/cc.alps/cc.alps/

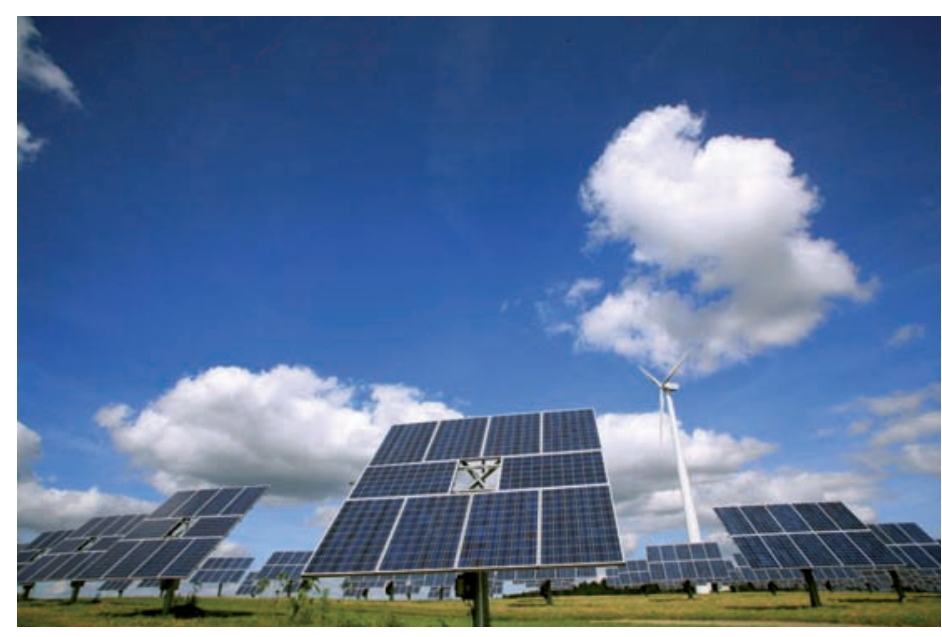

Fig. 1: Solar Energy Fields - a New Perspective for Land Use in Rural Areas? Source: CIPRA International.

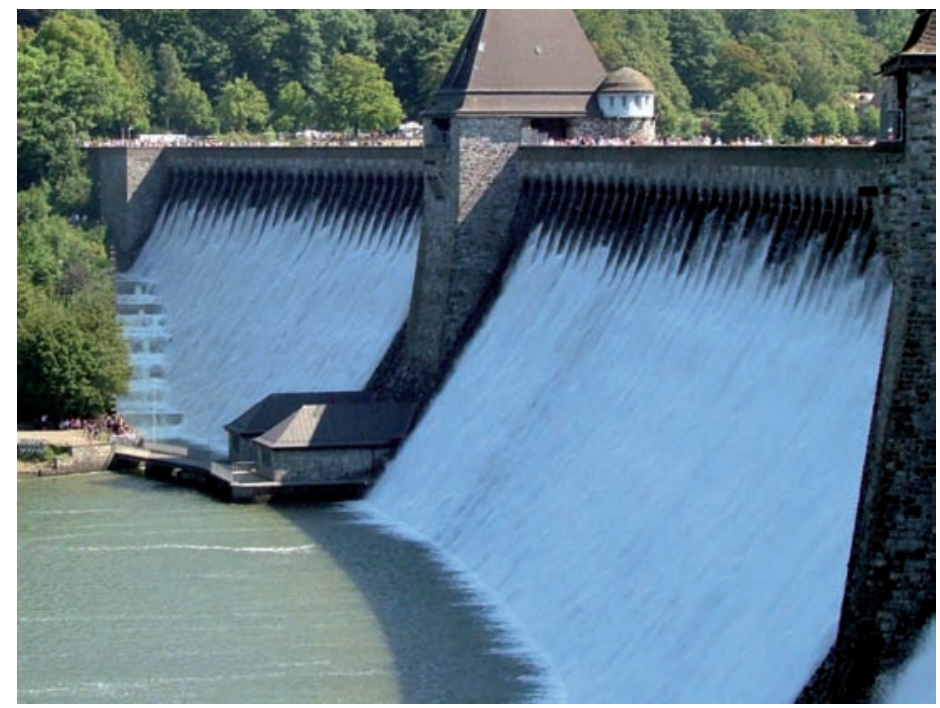

Fig. 2: Hydropower Plants - a New Old Conflict with Nature Protection. Source: CIPRA International.

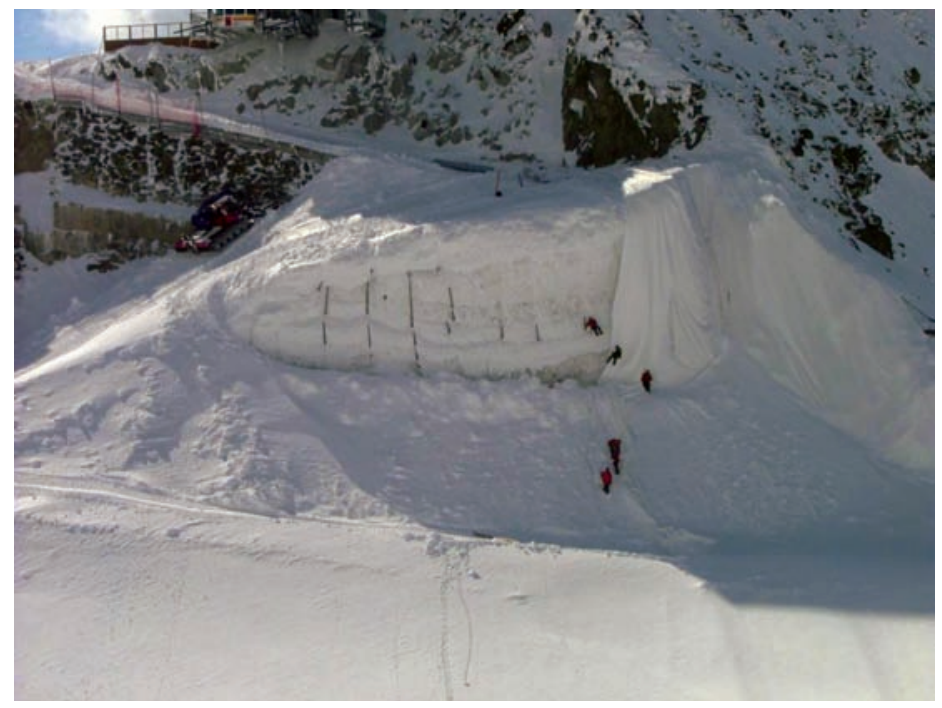

Fig. 3: Glacier Protection Sheets - an Adequate Strategy to Fight against Melting Glaciers? Source: CIPRA International. 


\title{
2/4 Alpine Club Yearbooks, Journals and Other Heritage Data: Digitisation and Scientific Analysis
}

\author{
Presentation: Martin Volk, Noah Bubenhofer \\ Input: Hanno Biber, Georg Glasze, Annika Mattissek
}

In the age of "Google Books", the digitisation of historical printed material is an important task for libraries and publishers. New scanning and OCR technologies make it possible to produce high quality facsimiles and processable text collections from old documents. But this is only the starting point for intelligent text analysis and data mining. Advanced methods from computational and corpus linguistics allow us to enrich digital text automatically with meta-information. These include linguistic features like parts-of-speech, semantic features like proper noun classes as well as temporal and geographic references.

In the Swiss project "Text+Berg" (www.textberg. ch), we are digitising and annotating the yearbooks of the Swiss Alpine Club from 1864 to today. Each yearbook consists of 300 to 600 pages and contains reports on mountain expeditions, culture of mountain peoples as well as the flora, fauna and geology of the mountains. The corpus preparation presented interesting challenges in automatic OCR correction, language identification, and text structure recognition which we have described in detail (Volk et al. 2010).

As of May 2010 we have scanned and OCR-converted 142 books from 1864 to 1982 . We have digitized 90 mixed-language books from the period before 1957. From then to 1982 we have 52 parallel French and German versions of the yearbooks. Overall we have scanned nearly 70,000 pages. This has resulted in 6,101 articles in German, 2,659 in French, 155 in Italian, 13 in Romansch, and 3 in SwissGerman, summing to a total of around 25 million words. Our translated corpus currently contains 701 articles amounting to 2.6 million words in French and 2.3 million in German. This allows for interesting cross-language comparisons and may serve as training material for statistical machine translation systems. We will soon add the French Echo des Alpes yearbooks (1871 to 1924) and the English texts from the British Alpine Club to our corpus.

Our corpus annotation allows for new approaches to text analysis and information retrieval: Using automated methods which discover language patterns, questions about the content, the stylistic nature or rhetorical strategies can be answered. This helps us to detect the rise and fall of topics like ecology, environmental protection or climate change (Bubenhofer 2009).
One of the goals of the Text+Berg project is automatic geo-tagging of the toponyms in the corpus. First experiments showed that geo-tagging of mountaineering reports pose special problems due to the denseness and fine granularity of references to all kinds of geographical objects (mountains, glaciers, rivers, cabins, routes, etc.).

In the workshop we will present the technical aspects of the digitisation and annotation, but we will also demonstrate how these heritage data can be analysed automatically for research in the social and natural sciences. The moderators' presentation on the Text+Berg corpus will be complemented by two input speakers:

\section{Alpine Texts from the "AAC-Austrian Academy Corpus" (Hanno Biber)}

The "AAC-Austrian Academy Corpus" is a large digital text corpus operated by the "Institute for Corpus Linguistics and Text Technology" of the "Austrian Academy of Sciences" in Vienna. The texts integrated into the AAC stemming from the last 150 years are predominantly German language texts and are of considerable historical and cultural significance.

Thousands of literary objects by thousands of authors have been collected, representing an astonishing range of different text types from all over the German speaking world. Among the sources, which cover manifold domains and genres, there are newspapers, literary journals, novels, dramas, poems, advertisements, essays, travel accounts, cookbooks, pamphlets, political speeches as well as plenty of scientific, legal, and religious texts, to name just a few. A great number of reliable resources for investigations into the linguistic and textual properties of these texts and into their historical and cultural quality can be provided. A segment of these texts is related to the thematic complex of Alpine literature. The various paths leading to this specific thematic complex within the texts of the "AAC - Austrian Academy Corpus" will be presented. The AAC's text technology working group has been working on issues of digitisation of historical language data, establishing efficient workflows as well as developing usable software and web interfaces. Two exemplary digital editions, the AAC-FACKEL and the BRENNER ONLINE editions 
will be presented in order to show possible solutions for the presentation of Alpine texts.

\section{Discursive Changes in Society-nature-relationships - the Example of the Alps (Georg Glasze, Annika Mattissek)}

Within geography analyses of the relationships between social processes and the physical environment are traditionally of great importance. In the course of the cultural and linguistic turn, the question how social reality is produced in language and in particular, how "nature" is constituted and which relationships to the "natural" environment are thus established come to the fore.

These questions about the discursive constitution of society-nature-relations are relevant, since they determine which practices, views and decisions are considered to be appropriate and "right" in a given context. With respect to the Alps these discourses affect for example, which land uses are assigned priority (e.g. how the relations between nature conservation, tourism and traffic are determined), which groups of persons follow which activities etc.

The high and increasing membership numbers of the Alpine Clubs show that these are not only associations with a long tradition but that they also hold a central position within society. Accordingly their publications mirror a number of trends and debates, which are or have been central for the social usage of the Alps. The text corpus with the yearbooks of the Swiss Alpine Club covers a long period of time and thus provides the possibility to analyze the changes in the relationship between socio-political contexts on the one hand and the social imaginations of nature and the Alps on the other hand. In particular the following questions can be addressed:

Which changes in the understandings of "nature" in general and high mountains and the Alps in particular can be traced with the help of the corpus? Which symbolisms are dominant and what is their relationship to the socio-political context - e.g. analysis of

- discursive references to the nation state and nationalism

- criticism against and counter movement towards the industrial society and the rationalism of modernism

- emergence of nature and climate conservation debates (change from space as having to be conquered to having to be protected and conserved)

- relationship between conceptions of nature as counter space of capitalist social relations vs. consumable space for individual self-fulfillment.

How have practices of the usage of nature in general and mountaineering in particular changed over time? Which identity constructions and ideals, which processes of inclusion and exclusion have been crucial? E.g. analysis of

- gender-identity constructions (mountaineering as male sport, aesthetics of heroism etc.)

- conflicts between generations

- conflicts between "conservative" and "leftishalternative" tendencies.

\section{Discussion}

The discussion should then address the following questions:

1. Which sources (journals, books etc.) from the Alpine clubs should be digitised? Which sources are most interesting for the research community?

2. How can one build a large text corpus of Alpine texts?

3. What new fields of research can be focused on, using rich annotated historical corpora, especially in the field of cultural geography and discourse analysis considering the cultural and linguistic turn?

4. Which additional methods of text analysis are desirable?

\section{References}

Bubenhofer, N. (2009): Sprachgebrauchsmuster. Korpuslinguistik als Methode der Diskurs- und Kulturanalyse (Sprache und Wissen 4). De Gruyter, Berlin/New York.

Volk, M., N. Bubenhofer, A. Althaus et al. (2010): Challenges in Building a Multilingual Alpine Heritage Corpus. In: Proceedings of LREC, Malta. 
